\section{Nos August 2019 Research}

\section{What are our priorities?}

The National Institute for Occupational Safety and Health (NIOSH) Center for Occupational Robotics Research (CORR) addresses the safety of today's workers who use, wear, or work near robots by working in partnership with academic researchers, trade associations, robotics manufacturers, employers using robotics technology, integrators who set-up robotic systems in workplaces, labor organizations, and other federal agencies. The Center addresses traditional robots and emerging technologies such as collaborative robots, mobile robots, powered exoskeletons, and remotely controlled or autonomous vehicles and drones. The Center focuses on:

- The potential for robotics technologies to prevent worker injuries and musculoskeletal disorders

- Increasing understanding of human and robot interactions to ensure human worker safety

- Improving the ability to identify and track injuries involving robotics technologies

- Providing guidance on working safely with robotics technologies

\section{What do we do?}

- Monitor trends in robotics technologies and associated injuries.

- Evaluate robotics technologies as sources of and interventions for, workplace injuries and illnesses.

- Establish risk profiles of robotic applications in workplaces.

- Identify research needs and conduct studies to improve the safety, health, and well-being

\section{What have we accomplished?}

- Presented a webinar on emerging robotics technologies and implications for worker safety and health to NIOSH-funded Education and Research Centers.

- The Washington State Fatality Assessment and Control Evaluation (FACE) program, funded by $\mathrm{NIOSH}$, published a summary of a 2015 worker death involving a driverless forklift. This fatality occurred despite engineering controls. Recommendations focused on following manufacturer recommendations and worker training.

\section{What's next?}

- Expand formal partnerships to collaborate on the safe development and deployment of robotics technologies.

- Publish a summary of robot-related injuries.

- NIOSH-funded researchers from the University of Utah will publish simulation-based research on new algorithms that can guide efforts to keep human workers safe when they work near robots. of humans working with robots and robotic technologies.

- Support the development and adoption of consensus safety standards.

- Develop and communicate best practices, guidance, and training for safe interactions between human workers and robots/robotics technologies.

\section{At-A-Glance}

The Center for Occupational Robotics Research, established in September 2017, provides scientific leadership to guide the development and use of occupational robots that enhance worker safety, health, and well-being. The Center includes multi-disciplinary scientists from across NIOSH. This snapshot shows recent accomplishments and upcoming work

Estimated annual worldwide supply of industrial robots 2011-2017 and 2018-2021* (in thousands of units)

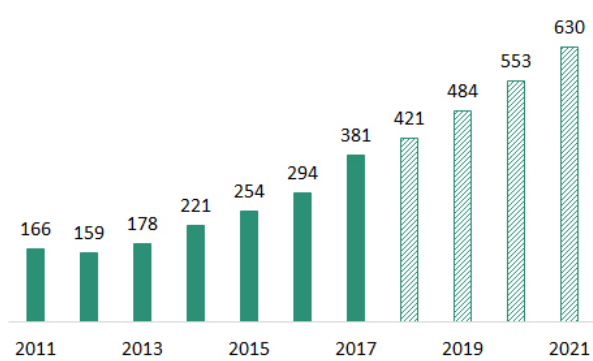

Source: International Federation of Robotics [2018]. Executive Summary World Robotics 2018 Industrial Robots.

*2018-2021 are projected numbers

\section{Traditional versus collaborative industrial} robots in units sold worldwide*

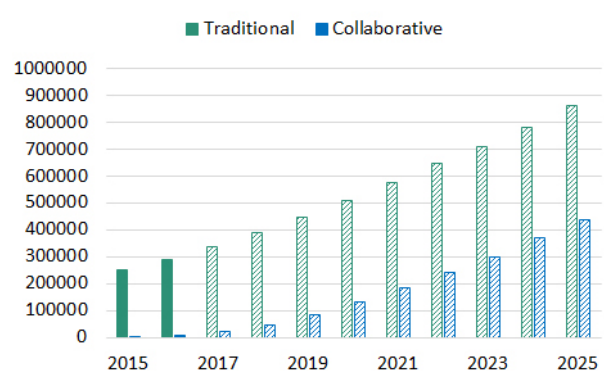

Source: Loup Ventures [2017]. Industrial: Robotics Outlook 2015. *2017-2025 are projected numbers safety standard. Also participated on a new ASTM committee developing exoskeleton standards. These standards will be used by manufacturers, integrators, and users of the technologies. research needs that complement robot safety

Participated on ANSI consensus standards committees revising traditional robot safety standards and developing a new mobile robot

Projected worldwide drone market by industry/function, 2016-2020 (in billions)

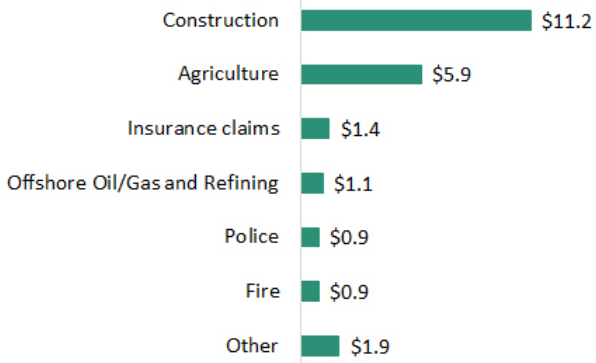

Co-publish proceedings from the 2018 Ergo-X Symposium: Exoskeletons in the Workplace Assessing Safety, Usability, \& Productivity, in collaboration with the Human Factors and
Ergonomics Society.

- Contribute to a guidance document on working safely with robots as part of an Alliance between the Occupational Safety and Health Administration (OSHA), Robotic Industries Association (RIA), and NIOSH.

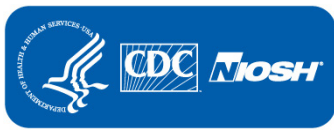

Centers for Disease Contro and Prevention

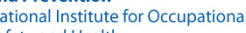
Safety and Health
To learn more, visit www.cdc.gov/niosh/topics/robotics/

Mention of any company or product does not constitute endorsement by the National Institute for Occupational Safety and Health, Centers for Disease Control and Prevention.
https://doi.org/10.26616/NIOSHPUB2019162

DHHS (NIOSH) Publication No. 2019-162 